\title{
Copper Metal Removal using Sludge Activated Carbon Derived from Wastewater Treatment Sludge
}

\author{
Ibrahim Umar Salihi ${ }^{1,}$, , Shamsul Rahman Mohamed Kutty², and Hisyam Hussin Mohd \\ Ismail $^{3}$ \\ ${ }^{1}$ Civil Engineering Department, Faculty of Engineering, Bayero University, Kano, P.M.B 3011, \\ Gwarzo road, Kano, Nigeria. \\ ${ }^{2}$ Civil and Environmental Engineering Department, Universiti Teknologi PETRONAS, 32610 Bandar \\ Seri Iskandar Perak, Darul Ridzuan, Malaysia
}

\begin{abstract}
In Malaysia, according to perspective sludge production factor (SPF), wastewater treatment plants produces about 5.3 million $\mathrm{m} 3$ of sewage sludge annually, most of this sludge are being wasted (unused) in the landfills. This study employed the use of dry activated sludge as low-cost adsorbent for the removal of copper $\mathrm{Cu}$ (II) from wastewater. Adsorption of $\mathrm{Cu}$ (II) by sludge activated carbon (SAC) was conducted using batch tests. The effect of contact time and adsorbent dosage on the removal of $\mathrm{Cu}$ (II)) from wastewater were investigated. Initial metal concentration was maintained at $100 \mathrm{mg} / \mathrm{L}$. The removal efficiency was found to have relations with the initial $\mathrm{Cu}$ (II) concentration, contact time as well as the SAC dosage. The adsorption kinetics of the $\mathrm{Cu}$ (II) by SAC was found to follow pseudo-second-order kinetic model, indicating chemisorption process. The adsorption isotherms studies indicated that the adsorption of $\mathrm{Cu}$ (II) by SAC adsorbent was well described by Langmuir isotherm model having correlation of determination $\left(\mathrm{R}^{2}\right)$ value of 0.9985 at $12 \mathrm{hrs}$ equilibrium period. Optimum conditions for $\mathrm{Cu}$ (II) removal was achieved at SAC dosages of $10 \mathrm{~g} / \mathrm{L}$, contact time 12 hours and at initial $\mathrm{Cu}$ (II) concentration of $100 \mathrm{mg} / \mathrm{L}$, respectively. The study indicated that sludge activated carbon can be used as an adsorbent for the removal of $\mathrm{Cu}$ (II) from aqueous solution.
\end{abstract}

\section{Introduction}

In recent years, there has been a tremendous interest in the bio-adsorption approaches, from dry activated sludge which involving the process of converting sludge into dry activated carbon which are efficient in removing heavy metals from aqueous solutions. The level of water contamination is one of the key topics that have attracted much attention globally.

\footnotetext{
Corresponding author: iusalihi@gmail.com
} 
Activated carbon is a carbonaceous adsorbent with a highly developed porous structure. Its effectiveness in removing pollutants through adsorption concept process has been found superior to many other techniques because of the high quality of the effluent achieved, simplicity of design, ease of operation and insensitivity to toxic substances. The mechanisms of surface adsorption are based upon physical and chemical interactions between metal and activated carbon surface and they are much more dynamic than assumed in the equilibrium models (Flouty and Estephane, 2012). With growth development in the country, the volume of wastewater generated increase annually and the volume of sludge produced from wastewater treatment process are proportionately increased. This initiate so much worries to communities in Malaysia, based on perspective sludge production factor (SPF), about 5.3 million $\mathrm{m} 3$ of excess sludge is produced annum, this comprises of sludge produced from domestic and sewage companies such as households, universities hostels, Indah Water Konsortium (IWK), respectively. Most of this sludge is being wasted in the landfill. Activated sludge is an effective biomaterial for biosorption or bioleaching of the metal ions such as $\mathrm{Cu}$ (II) from wastewater.

The removal of heavy metals from wastewater using activated sludge is highly efficient and has low installation, operation and maintenance costs (Buyukgungor and Gurel, 2009; Gavrilescu, 2004; Hussein et al., 2005). The aim of the present research was to investigate biosorption of $\mathrm{Cu}$ (II) ions by sludge activated carbon (SAC). Effects of contact time and $\mathrm{SAC}$ dosage on biosorption of $\mathrm{Cu}$ (II) ions were studied.

\section{Materials and method}

\subsection{Preparation of the Adsorbent}

Sludge was obtained from sludge drying bed of sewage treatment plant (STP) of Universiti Teknologi PETRONAS, Malaysia. The sludge was manually grinded to an average size of 5 $\mathrm{cm}$. The sludge was dried in an oven at $105^{\circ} \mathrm{C}$ for 24 hours until all moisture evaporated and a constant weight was achieved. About $10 \mathrm{~g}$ of the dried sludge was weighed and incinerated in a tube furnace at a temperature of $500{ }^{\circ} \mathrm{C}$ for a period of 3 hours. Heating rate of $10^{\circ} \mathrm{C} / \mathrm{min}$ and nitrogen flow rate of about $100 \mathrm{~mL} / \mathrm{min}$ was maintained during the production process. The resulting sludge activated carbon (SAC) was crushed and sieved into powder size of about $150 \mu \mathrm{m}$. The SAC powder was stored in a desiccator before use.

\subsection{Preparation of the Adsorbate}

A stock solution was prepared by dissolving calculated weigh of copper (II) chloride salt in $1 \mathrm{~L}$ of distilled water to give a concentration of $1000 \mathrm{mg} / \mathrm{L}$. To obtain further required concentrations, the stock solution was diluted appropriately. The chemical employed are of analytical grade, obtained from Merck (Germany).

\subsection{Batch Experiments}

Batch adsorption experiments were carried out using SAC as adsorbent. A $100 \mathrm{~mL}$ synthetic copper (II) solution with predetermined metal ion concentrations was placed in a series of $250 \mathrm{~mL}$ Erlenmeyer flasks. The flasks were agitated using an orbital shaker (Protech Model $722)$ at $150 \mathrm{rpm}$ at room temperature $\left(25 \pm 1^{\circ} \mathrm{C}\right)$. At the end of scheduled agitation times, the mixtures were separated using Whatman's glass microfiber filters paper $(\mathrm{GF} / \mathrm{C})$. Filtered solutions were analysed for residual copper (II) concentration using a spectrophotometer (DR 2800 Hach). 


\subsection{Analytical Methods}

Adsorption experiments were conducted to study the effect of initial copper concentration and contact time. The experiment was conducted by placing $0.5,1.0,2.5,5.0,7.5$ and 10.0 $\mathrm{g} / \mathrm{l}$ of SAC into series of $250 \mathrm{ml}$ Erlenmeyer flasks. A $100 \mathrm{ml}$ of synthetic copper solutions was measured and added into the flasks. The flasks were clamped in an orbital shaker and agitated for 3, 6, 8, 12 and 24 hours, respectively. The agitation speed was maintained at 150 rpm throughout the study. The tests were run in triplicates at metal concentrations of 100 $\mathrm{mg} / \mathrm{l}$. At the end of the predetermined interval of time, samples were removed from the shaker and analyzed for residual copper concentration until equilibrium was attained. Equations (1) and (2) were used to compute the metal adsorption efficiency and adsorption capacity of SAC.

$R=\frac{\left(C_{i}-C_{e}\right)}{C_{i}} \times 100 \%$

where, $\mathrm{R}$ is the copper removal efficiency $(\%), \mathrm{Ci}$ is the initial copper concentration and $\mathrm{Ce}$ is the residual copper $(\mathrm{mg} / \mathrm{L})$ concentrations at equilibrium.

$$
Q_{c}=\frac{\left(C_{i}-C_{e}\right)}{W} V
$$

where, Qc is the adsorbent adsorption capacity $(\mathrm{mg} / \mathrm{g}), \mathrm{Ci}$ is the initial copper concentration and $\mathrm{Ce}$ the residual concentration copper $(\mathrm{mg} / \mathrm{L})$ at equilibrium, $\mathrm{V}$ is volume of aqueous Copper solution (L) and $\mathrm{W}$ mass of $\mathrm{SAC}(\mathrm{g})$.

\section{Results and Discussions}

\subsection{Effect of Contact Time}

The equilibrium contact time is an important parameter for adsorption process. In order to determine the effect of contact time, biosorption was performed for 3, 6, 8, 12 and $24 \mathrm{~h}$. Fig. 1 demonstrates contact time effects on biosorption of $\mathrm{Cu}$ (II) onto SAC. Removal efficiency rapidly increased during the initial adsorption stage and reached to $32 \%$ when contact time was $8 \mathrm{~h}$. The removal efficiency gradually increased with contact time and equilibrium was reached after $12 \mathrm{~h}$ for the rest of the dosage. At initial stage, adsorption of $\mathrm{Cu}$ (II) onto monolayer surface of SAC may explain the rapid increase in removal efficiency. After that the monolayer surface was saturated, the $\mathrm{Cu}$ (II) ions were gradually adsorbed into the inner part of SAC with diffusion; therefore lower biosorption rate was obtained.

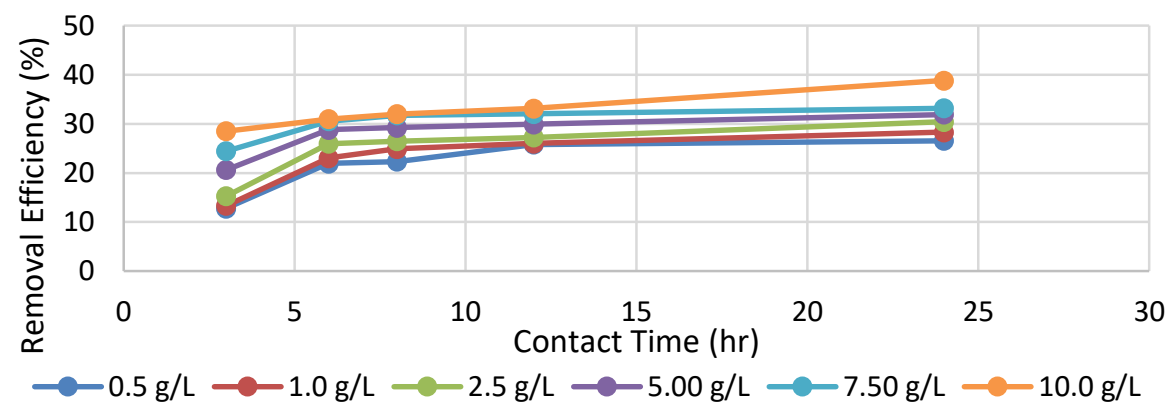

Fig. 1. Removal Efficiency vs Contact Time 


\subsection{Effect of SAC dosage}

Effect of SAC dosage on the removal of $\mathrm{Cu}$ (II) at $100 \mathrm{mg} / \mathrm{L}$ concentration was also investigated. Fig. 2 shows the removal of $\mathrm{Cu}$ (II) at different SAC dosage. Residual copper concentration decreases with an increase in SAC dosage until equilibrium removal was attained. With the increased in adsorbent dosage, more surface areas are available for the adsorption of metal ions.

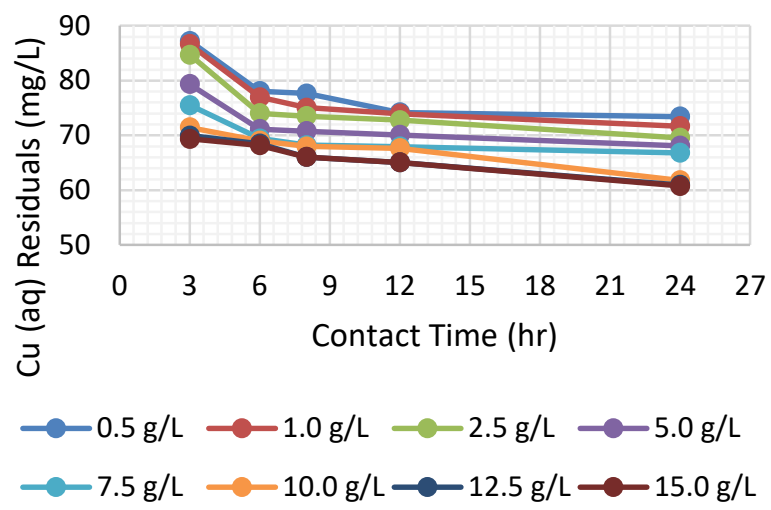

Fig. 2. Removal Copper (aq) Residual vs Contact Time at different dosages of SAC

\subsection{Adsorption Isotherm}

The relationship between adsorbate concentration and its degree of adsorption onto the surface of the adsorbent at a fixed temperature is mainly established by adsorption isotherm studies. In this study, Langmuir and Freundlich isotherm models were used to measure the adsorption capacity of SAC for removal of $\mathrm{Cu}^{2+}$ from aqueous solution.

Langmuir model is a frequently used model which describes heavy metals sorption unto biosorbent. Langmuir model operates based on three distinct assumptions viz; that all surface sites are the same and can occupy one adsorbed atom, it is limited to monolayer coverage adsorption and capability of a molecule adsorbed at a given site is not dependent on the occupancy of its adjoining sites. Langmuir model is valid for monolayer adsorption containing finite number of identical biosorption sites. In this case interaction between adsorbate particles is negligible. The Langmuir model is given by the following equation (Langmuir, 1918):

$$
\frac{C_{e}}{A_{q}}=\frac{1}{b_{L} q_{m}}+\frac{C_{e}}{q_{m}}
$$

where $A_{q}$ is the quantity of pollutant adsorbed per gram of adsorbent $(\mathrm{mg} / \mathrm{g}), \mathrm{b}_{\mathrm{L}}$ is the Langmuir constant for equilibrium, $\mathrm{q}_{\mathrm{m}}$ is the adsorbate quantity that is required for a monolayer formation and $\mathrm{C}_{e}$ is the concentration of residual metal at equilibrium $(\mathrm{mg} / \mathrm{L})$. Thus, plot of $\mathrm{C}_{\mathrm{e}} / \mathrm{q}_{\mathrm{e}}$ against $\mathrm{C}_{\mathrm{e}}$ will be a straight line with a slope of $1 / \mathrm{q}_{\mathrm{m}}$ and intercept of $1 / b_{L} q_{m}$ [31]. This important characteristic of the Langmuir isotherm can be expressed in terms of a dimensionless factor, $\mathrm{R}_{\mathrm{L}}$ [44], which is defined as

$$
R_{L}=\frac{1}{1+b_{L} q_{m}}
$$


The $R_{L}$ values indicate the type of adsorption as either unfavorable $\left(R_{L}>1\right)$, linear $\left(R_{L}=1\right)$, favorable $\left(0<\mathrm{R}_{\mathrm{L}}<1\right)$, or irreversible $\left(\mathrm{R}_{\mathrm{L}}=0\right)$.

The equilibrium data were analyzed using the linearized form of Langmuir adsorption isotherm Eq. (3). Langmuir constants and monolayer biosorption capacity $\mathrm{q}_{\mathrm{m}}$ were calculated from the slope and intercept of the plot $\mathrm{C}_{\mathrm{e}} / \mathrm{A}_{\mathrm{q}}$ versus Ce (Fig. 3). The Langmuir isotherm constants are shown in Table 1.

Freundlich isotherm model is a commonly used model for describing adsorption equilibrium based on empirical equation. Freundlich isotherm model have the ability of unfolding adsorption related to both organic and inorganic composites on a wider range of adsorbents inclusive of biosorbent. The Freundlich isotherm model is employed to describe heterogeneous surfaces that represents the binding sites are not equivalent and/or independent. This model considers repulsive interactions between adsorbed solute particles (Freundlich, 1906; Sinha et al., 2012). Freundlich equation is given as follows:

$$
\begin{aligned}
& \log A_{q} \\
& =\log K_{F}+\frac{1}{n} \log C_{e}
\end{aligned}
$$

where $\log A_{q}$ is the quantity of the adsorbed pollutant per gram of the adsorbent ( $\mathrm{mg} / \mathrm{g}$ ), $\mathrm{C}_{\mathrm{e}}$ is the equilibrium concentration $(\mathrm{mg} / \mathrm{L}), K_{F}$ and $n$ are Freundlich constants. Plot of $\log \mathrm{A}_{\mathrm{q}}$ against $\log \mathrm{C}_{\mathrm{e}}$ has $1 / \mathrm{n}$ as slope and $\log \mathrm{K}_{\mathrm{F}}$ as its intercept.

As shown in Fig. 4, the plot of $\log \mathrm{q}_{\mathrm{e}}$ versus $\log \mathrm{C}_{\mathrm{e}}$ was fitted linearly for Freundlich isotherm model. Freundlich isotherm parameters, $\mathrm{K}_{\mathrm{F}}$ and $1 / \mathrm{n}$ were calculated from the slope and intercept of linear plots of $\log \mathrm{q}_{\mathrm{e}}$ and $\log \mathrm{C}_{\mathrm{e}}$ (Fig. 4).

Table 1 shows the coefficient values obtained from the plots of both Freundlich and Langmuir isotherm models on the adsorption of $\mathrm{Cu}^{2+}$ onto SAC adsorbent.

From Table 1, it can be seen that the coefficients of determination $\mathrm{R}^{2}$ values from the Langmuir isotherm are higher compared with Freundlich isotherms. This suggests that the experimental data obtained from SAC follows Langmuir isotherm model compared to Freundlich isotherm model. This indicates the monolayer coverage of $\mathrm{Cu}^{2+}$ ions on the homogeneous surface of SAC. The Freundlich intensity values are in the range of 0.0874 to 0.1036 ; this indicates a favorable type of adsorption.

Table 1. Freundlich and Langmuir isotherm for $\mathrm{Cu}^{2+}$ adsorption

\begin{tabular}{ccccc|cccc}
\hline \multicolumn{4}{c|}{} & \multicolumn{4}{c}{ Langmuir } \\
\hline Hour & $\mathrm{n}$ & $\mathrm{K}_{\mathrm{F}}$ & $\mathrm{R}^{2}$ & Equation & $\mathrm{q}_{\mathrm{m}}$ & $\mathrm{R}^{2}$ & $\mathrm{R}_{\mathrm{L}}$ & Equation \\
\hline 3 & 0.1445 & $5.728 \mathrm{x} 10-3$ & 0.7099 & $\mathrm{y}=6.9181 \mathrm{x}-12.242$ & 0.755 & 0.997 & 0.0107 & $\mathrm{y}=-1.3245 \mathrm{x}+222.73$ \\
6 & 0.1036 & $8.770 \mathrm{x} 10-3$ & 0.9142 & $\mathrm{y}=9.652 \mathrm{x}-17.057$ & 0.2445 & 0.989 & 0.0638 & $\mathrm{y}=-4.0883 \mathrm{x}+402.62$ \\
8 & 0.0977 & $9.550 \mathrm{x} 10-2$ & 0.7954 & $\mathrm{y}=10.24 \mathrm{x}-18.02$ & 0.253 & 0.967 & 0.0545 & $\mathrm{y}=-3.953 \mathrm{x}+362.78$ \\
12 & 0.0992 & $2.630 \mathrm{x} 10-2$ & 0.6714 & $\mathrm{y}=10.085 \mathrm{x}-17.58$ & 0.2708 & 0.988 & 0.0339 & $\mathrm{y}=-3.6925 \mathrm{x}+335.67$ \\
24 & 0.0874 & $1.274 \mathrm{x} 10-2$ & 0.6969 & $\mathrm{y}=11.447 \mathrm{x}-19.895$ & 0.4538 & 0.998 & 0.0301 & $\mathrm{y}=-2.2034 \mathrm{x}+214.91$ \\
\hline
\end{tabular}




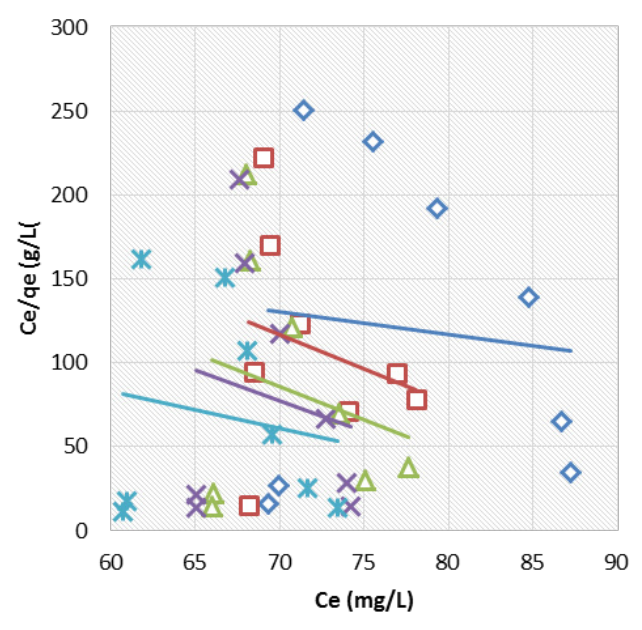

$\diamond 3$ hour $\square 6$ hour $\triangle 8$ hour $\times 12$ hour $* 24$ hour

Fig. 3. Langmuir Isotherm graph

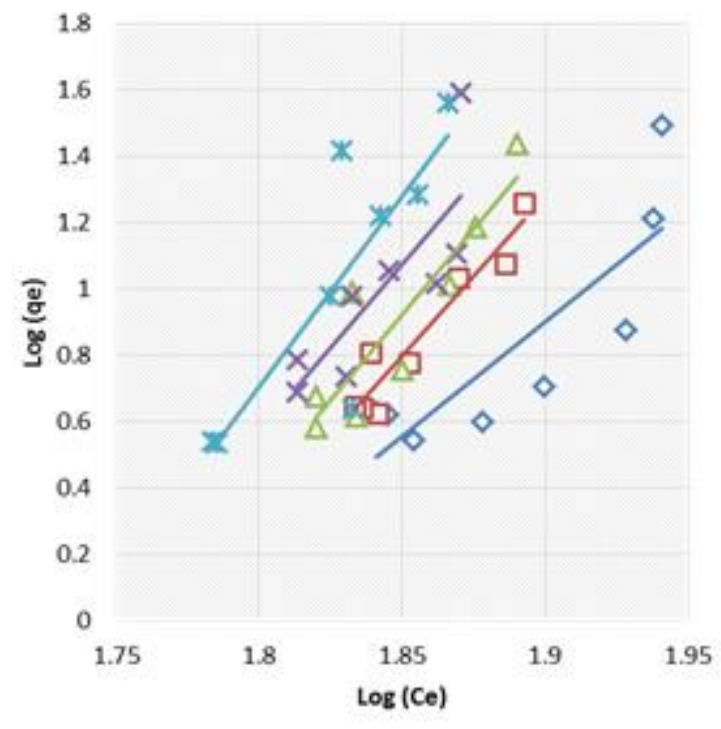

Fig. 4. Freundlich Isotherm graph

\subsection{Kinetic Studies}

Kinetics of $\mathrm{Cu}^{2+}$ adsorption using SAC was also studied in the present work. Lagergren first and second order models were employed. The pseudo-first-order kinetic model is expressed generally as Equation (6):

$$
\begin{aligned}
\log \left(q_{e q}-q_{t}\right)= & \log q_{e q} \\
& -\frac{k_{1}}{2.303}
\end{aligned}
$$


where $q_{e q}$ is the quantity of adsorbate adsorbed at equilibrium $(\mathrm{mg} / \mathrm{g}), q t$ is the amount adsorbate adsorbed at a given time $t$ and $k_{l}$ is the first order constant rate of adsorption (min1). The plot of $\log \left(q_{e q}-q_{t}\right)$ against time should be linear with $k_{1} / 2.303$ and $\log q_{e q}$ representing the slope and intercept of the line.

Pseudo-second-order kinetic model was also used to analyze the data from the experiments and the mechanism that best fits the data was determined. Linearized form of pseudo-second-order kinetic model is shown in Equation (7). The slope and the intercept of the equation were determined by plotting $t / q_{t}$ against time.

$$
\frac{\mathrm{t}}{q_{t}}=\frac{1}{k_{2} q_{e q}^{2}}+\frac{1}{q_{e q}}
$$

where $k_{2}$ is the second order adsorption rate constant (g/ mg.min) and $q_{e q}$ is the adsorbed quantity of pollutant at equilibrium $(\mathrm{mg} / \mathrm{g})$. The second order plots of $t / q_{t}$ against time will yield a straight line.

Fig 5 and 6 shows Pseudo $1^{\text {st }}$ and $2^{\text {nd }}$ Order graphs. From the plots, the pseudo-secondorder kinetic model presented high values of coefficient of determination $\left(R^{2}\right)$. All the values were close to unity. There was a deviation between the experimental $q_{e, \text { exp }}$ values and the calculated $q_{e, c a l}$ values for the pseudo-first-order kinetic model. This indicates a poor fit of the pseudo-first-order model to the experimental data. On the other hand, the calculated $q_{e}$, cal values obtained from pseudo-second-order model agreed effectively with the experimental $q_{e, \exp }$ values. Therefore, it can be concluded that the adsorption of $\mathrm{Cu}^{2+}$ ions onto SAC is a pseudo-second-order reaction model. This suggests that the rate limiting step is chemisorption or chemical adsorption that involves valence forces through electrons exchange between the adsorbent $(\mathrm{SAC})$ and the adsorbate $\left(\mathrm{Cu}^{2+}\right)[16]$.

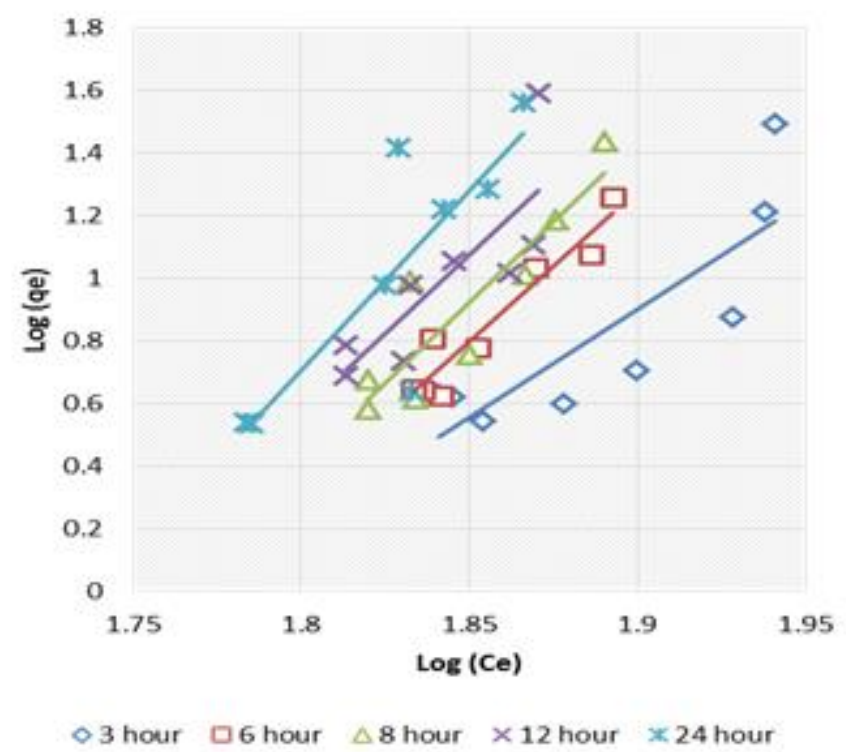

Fig. 5. Pseudo first order plot 


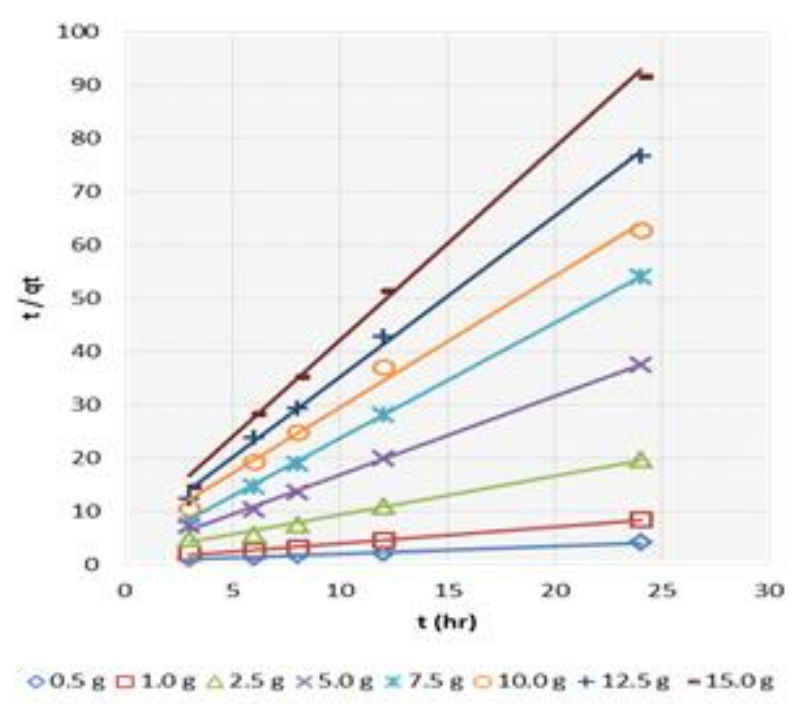

Fig. 6. Pseudo second order plot

\section{CONCLUSION}

The present study shows that activated carbon produced from the sugarcane bagasse using tube furnace can be engaged as an environment friendly and low cost adsorbent for the removal of $\mathrm{Cu}^{2+}$ ions from aqueous solution. The study on the effect of $\mathrm{pH}$ revealed that the competitions between $\mathrm{H}^{+}$and metal ions at low $\mathrm{pH}$ values are the main leading factors that affects the adsorption characteristics of SAC. Equilibrium time of 12 hours was considered optimum for the adsorption of $\mathrm{Cu}^{2+}$ by SAC. Number of adsorption sites increased due to an increase in SAC dosage and optimum removal efficiency of $50.8 \%$ was achieved at SAC dosage of $10 \mathrm{~g} / \mathrm{L}$. The kinetics analysis results obtained from pseudo-first-order and pseudosecond-order showed that the experimental data fitted well with pseudo-second-order kinetic model. The obtained experimental uptake capacities were almost the same as the calculated values from pseudo-second-order kinetic models. Removal isotherm for $\mathrm{cu}^{2+}$ using SAC was well described by Langmuir isotherm models with correlation coefficients of 0.988 at $12 \mathrm{hrs}$ equilibrium time. This indicates the monolayer coverage of $\mathrm{Cu}^{2+}$ ions on the homogeneous surface of SAC.

\section{References}

1. Abia, A. A. A bioseparation process for removing heavy metals from waste water using biosorbents, 5, 1167-1179 (2006).

2. Babel, S., \& Kurniawan, T. A. Low-cost adsorbents for heavy metals uptake from contaminated water: a review, 97, 219-243 (2003).

3. Bajpai, S. K., \& Jain, A. Removal of copper ( II ) from aqueous solution using spent tea leaves ( STL ) as a potential sorbent, 36, 3, 221-228 (2010).

4. Copper, O., National, E. P. A., List, P., States, U., Rico, P., Islands, V., ... Coast, N. E. 6 . POTENTIAL FOR HUMAN EXPOSURE, (Ii), 121-191 (2004).

5. Federation, W. E. Standard Methods for the Examination of Water and Wastewater Part 1000 Standard Methods for the Examination of Water and Wastewater (1999).

6. Garc1, A. I. Adsorption of heavy metals onto sewage sludge-derived materials, 99, 
6332-6338 (2008).

7. Kaur, R., Wani, S. P., Singh, A. K., \& Lal, K. Wastewater production, treatment and use in India, 1-13. https://doi.org/10.1016/j.watres.2014.11.002 (2011).

8. Martin, M. J., Artola, A., Balaguer, M. D., \& Rigola, M. Activated carbons developed from surplus sewage sludge for the removal of dyes from dilute aqueous solutions.

Chemical Engineering Journal, 94, 3, 231-239. https://doi.org/10.1016/S1385$\underline{8947(03) 00054}$ (2003).

9. Otero, M., Rozada, F., Morán, A., Calvo, L. F., \& García, A. I. Removal of heavy metals from aqueous solution by sewage sludge based sorbents : competitive effects. DES, 239, (1-3), 46-57 https://doi.org/10.1016/j.desal.2008.03.005 (2009).

10. Shokoohi, R., Saghi, M. H., Ghafari, H. R., \& Hadi, M. Biosorption of iron from aqueous solution by dried biomass of activated sludge, 6, 2, 107-114 (2009).

11. Simonin, J. On the comparison of pseudo-first order and pseudo-second order rate laws in the modeling of adsorption kinetics. Chemical Engineering Journal, 300, 254-263. https://doi.org/10.1016/j.cej.2016.04.079 (2016).

12. Tay, J. H., Chen, X. G., Jeyaseelan, S., \& Graham, N. Optimising the preparation of activated carbon from digested sewage sludge and coconut husk, 44, 45-51 (2001).

13. Wen, Q., Li, C., Cai, Z., Zhang, W., Gao, H., Chen, L., ... Zhao, Y. Bioresource Technology Study on activated carbon derived from sewage sludge for adsorption of gaseous formaldehyde. Bioresource Technology, 102, 2, 942-947. https://doi.org/10.1016/j.biortech.2010.09.042 (2011).

14. William, T., Albrecht, J., Addai-mensah, J., \& Fornasiero, D. (n.d.). Effect of pH, Concentration and Temperature on Copper and Zinc Hydroxide Formation / Precipitation in Solution, 1-10.

15. Zaini, M. A. A., Zakaria, M., Alias, N., Zakaria, Z. Y., Johari, A., Setapar, S. H. M., ... Yunus, M. A. C. Removal of heavy metals onto $\mathrm{KOH}$-activated ash-rich sludge adsorbent. Energy Procedia, 61, 2572-2575 https://doi.org/10.1016/j.egypro.2014.12.048 (2014).

16. Zare, H., Heydarzade, H., Rahimnejad, M., Seyfi, M., Mohsen, S., \& Tardast, A. Dried activated sludge as an appropriate biosorbent for removal of copper ( II ) ions. Arabian Journal of Chemistry, 8, 6, 858-864 https://doi.org/10.1016/j.arabjc.2012.11.019 (2015).

17. Zhang, F., Nriagu, J. O., \& Itoh, H. Mercury removal from water using activated carbons derived from organic sewage sludge, 39, 389-395. https://doi.org/10.1016/j.watres.2004.09.027 (2005).

18. A. W. Tan, B. H. Hameed, and A. L. Ahmad, "Equilibrium and kinetic studies on

19. basic dye adsorption by oil palm fibre activated carbon," Chemical Engineering

20. Journal, 127, pp. 111-119, 3/1/ (2007).

21. M. H. Isa, N. Ibrahim, Hamidi Abdul Aziz, M. N. Adlan, N. H. M. Sabiani, A. A. L. Zinatizadeh, et al., "Removal of chromium (VI) from aqueous solution using treated oil palm fibre," Journal of Hazardous Materials, 152, pp. 662-668, (2008).

22. M. Rafatullaha, O. Sulaimana, R. Hashima, and A. Ahmadb, "Adsorption of copper (II), chromium (III), nickel (II) and lead (II) ions from aqueous solutions by meranti sawdust," Journal of Hazardous Materials, 170, pp. 969-977, (2009). 